\section{UCDNN}

LIBRARY
University of Connecticut OpenCommons@UConn

Philosophy Articles

Philosophy Department

June 1998

\title{
Essential Properties and Coinciding Objects
}

Crawford Elder

University of Connecticut Department of Philosophy, crawford.elder@uconn.edu

Follow this and additional works at: https://opencommons.uconn.edu/philo_articles

\section{Recommended Citation}

Elder, Crawford, "Essential Properties and Coinciding Objects" (1998). Philosophy Articles. 6.

https://opencommons.uconn.edu/philo_articles/6 
Crawford L. Elder

Department of Philosophy, U-54

University of Connecticut

Storrs, Connecticut 06269-2054

U. S. A.

\section{Essential Properties and Coinciding Objects}

Common sense believes in objects which, if real, routinely lose component parts or particles. Statues get chipped, people undergo haircuts and amputations, and ships have planks replaced. Sometimes philosophers argue that in addition to these objects, there are others which could not possibly lose any of their parts or particles, nor have new ones added to them--objects which could not possibly have been bigger or smaller, at any time, than how they actually yere. ${ }^{1}$ (Sometimes the restriction on size is argued independently of the restriction on switches of parts. ${ }^{2}$ ) If these other objects are real at all, they are alarmingly abundant. Exactly where the statue sits, there sits a parcel or piece of clay which would cease to be itself, and hence cease to exist, were even so small a part as the statue's nose removed. ${ }^{3}$ In exactly the place where the recently reconditioned ship is found, there is a mass of wood which never contained, and never could contain, any particles of wood--or bits of wood-stuff--other than those it now has. ${ }^{4}$ Moreover, since masses of matter (or "aggregates") can continue to exist even if divided into separate parts, while parcels cannot, the abundance is two-fold: where every parcel is found, there is also a mass. ${ }^{5}$

But how can there be room for all these additional objects if, at any time, two different objects cannot occupy exactly the same place? Or, worse, if even some of these additional objects are real, how can room remain for familiar objects? Recent treatments of this ancient puzzle have urged that we retain both "the principle of one object to a place" and the other ontological assumptions which make that principle seem to force a choice between affirming the reality of familiar objects, and that of the strangely brittle intruders. ${ }^{6}$ But all the recent treatments have left standing the reality of at least some of these brittle objects. ${ }^{7}$ By doing so they have passed up what is, perhaps, the simplest and safest response to the ancient puzzle. That is to say that the so-called objects which could not possibly have any parts other than their actual ones, nor any size other than their actual one, simply do not exist. The main aim 
of this paper is to argue that this response is at least defensible; for the most part, the argument here will let the simplicity of this response, and its relative safety, speak for themselves.

Before beginning, I must give some specifics about the ontological assumptions which the argument is designed to protect, and about the brittle objects which are its main target.

The ontological assumptions are just those which make it seem that brittle objects, if real, leave no room in the world for so-called "mereologically incontinent" objects--that is, for familiar objects such as statues and ships, people and dogs. Most obviously, there is the assumption that no two objects can, as wholes and at the same time, occupy exactly the same place as one another. This assumption is not meant as a blanket denial that two sortals can be satisfied at exactly the same region of space and time. It is aimed specifically at the case in which satisfaction of one sortal seems to require, in what occupies such a region, one set of modal capacities--of abilities of survive, and vulnerabilities to destruction-while satisfaction of the other seems to require an incompatible set of modal capacities. Thus it seems that a statue must continue to be a statue, if it it is to continue to be at all; that so long as a particular aggregate of copper atoms continues to be the same aggregate, it continues to exist; and hence that if what occupies that spatial region gets flattened, it both ceases to exist, and continues to exist. The point is that the modal capacities, that would attach to the "two objects" which the assumption bans, must be ones which seem intuitively to obtain in re. If under certain circumstances an individual church would cease to be a church, while the building which occupies exactly the same region of space and time goes on being a building, there is little pressure to judge that what occupies that region has both ceased to exist, and continued to exist; an individual church can, after all, cease to be a church, without ceasing to exist altpgether. ${ }^{8}$ So this first assumption should perhaps be termed "the principle of one substance to a place". ${ }^{9}$ And the motivation for it is simply that it is better to resolve a philosophical problem than to evade it. The position that that region of space is occupied both by a 100-pound statue and by a 100pound aggregate of copper atoms receives confirmation from neither the weighing scale nor any other 
means of detection; its sole motivation is that unless one asserts it, one is facing a philosophical problem. It would be better to tackle the problem head on.

Second, and less obviously, there is the assumption that if an object exists at a time, it is wholly present at that time--in other words, that objects are not made up of temporal parts, no two of which are contemporaneous. This is the assumption which ensures that if two objects were at a given time to occupy exactly the same place, they would thereby violate the first assumption--it would be of no help at all that one of the objects outlasted the other. (Think of the mass of copper, which is "brittle" in that it cannot survive being diminished or having more copper added to it, but also manages to outlast the statue with which it temporarily coincides, when the statue gets flattened.) And the third main assumption is that the ban on two objects in exactly the same place applies even if the (putative) two objects are picked out by different sortals (e.g., "statue" and "mass of clay"). ${ }^{10}$ For what seems to need banning, when one thinks about brittle objects sitting exactly where familiar objects such as chairs and statues are, is that the very particles that completely compose the familiar objects (or the very same masses of stuff) should simultaneously compose objects having quite different modal capacities. This difference in modal capacities, between seemingly coincident objects, would be untouched if one limited "no two objects" to two objects of just the same sort.

What I am calling "brittle" objects themselves fall into three main types. The type most commonly discussed are those composed of parts, including both parcels and masses--and what is brittle about them is that they necessarily are composed of just those individual parts, of which in fact they are composed. On the more common version of such objects, replacing even one part, even by another that is qualitatively just alike, would bring it about that the original object no longer exists at all. On a less common version, the brittle object can exist only so long as it contains at least a specific proportion of its actual parts. ${ }^{11}$ The parts may be fairly large, such as the planks in the Ship of Theseus, or small, such as the particles recognized by atomic physics; they may in turn be composed of further parts, or may be "mereological atoms"; they may be parts of whose nature we should expect a future physics to apprise us, or they may be metaphysical "simples". 
But two other types of modally inflexible objects have been discussed, or suggested, in the recent literature, and they too threaten to crowd out familiar objects. The first are objects composed not of smallest parts at all, but of "atomless gunk", and what is brittle about them is that each_necessarily is composed of just the particular mass of stuff (or "gunk") of which it in fact is composed. ${ }^{12}$ Such objects may seem merely fanciful, but it has been argued that ontology cannot just take for granted that familiar objects such as people and statues are made up of smallest parts; we should have a position on whether there would be room in the world for such objects if it should turn out that the physical world is just extents of seamless stuff. ${ }^{13}$

Finally, there are objects brittle in the sense that each necessarily has, at any given time, exactly the shape and size which in fact it then has. These brittle objects are modeled after, but different from, what Mark Heller calls "hunks". ${ }^{14}$ "Hunks" are objects which do have temporal parts; so none is ever wholly present exactly where some familiar object is; so none ever threatens to crowd out a familiar object. But the whole essential nature of a "hunk" lies in the spatial character of each of its component stages, and this suggests a kind of brittle object which does pose a threat: objects which are wholly present at each moment of their existence, and have essentially, at each particular moment, exactly that shape and size which in fact they then have. Exactly where your recently reupholstered chair sits, for example, there would be such an object. The seat on your chair could have been thinner, at this very moment, by half an inch--and would have been, if the upholsterer had been stingy with the foam--but the contours of this object could not possibly have been different, now, from what in fact they are.

\section{II}

Might an object, in fact composed of just these particular parts, be necessarily composed of just these parts--might the composition be an essential property of the object? In the next section, I argue that the answer is No.

In the section after that, I confront the intuition that this table (for example) could not have existed--though a different table might have existed in its place--had it not been composed of just this 
wood. This intuition does not, indeed, say that this table must, to be itself, contain every last bit of wood, which in fact goes to compose it (or all of this mass of wood--wood might, for all this intuition says, be a form of "atomless gunk"). But it does seem to say that this table would not have existed, or been itself, had it not at least mainly been composed of just these bits (or this mass) of wood. I argue that what this intuition responds to is the fact that this table is wooden--is composed of some wood or other. There is actually no necessity that this table be composed of exactly this wood, as such. It's just that in most of the circumstances which we half-consciously envision, the only way for this table to go on being composed of some wood--or to have been, in the past, so composed--is for it to be (or to have been) composed of this wood. This wood is not required, so to speak, "by name"--by virtue of its numerical identity--but by virtue of the special circumstances most readily envisioned. Different circumstances can easily be imagined, which cancel the intuition that composition by just this wood is necessary.

In the penultimate section I consider the three-dimensional analogues of "hunks"--objects which do not insist on having numerically the same composition as what they actually have, but do insist on having shapes and sizes qualitatively the same as those which, at each moment they exist, they in fact have. I argue that no object can be essentially so characterized: the having, at such-and-such a time, of suchand-such a spatial extent is not part of an essential nature.

III

The idea that a material object might essentially be composed of just these (namely its actual) component parts--of all of them, or even of just a certain fraction of them--raises an ancient question. To what extent must the essential properties of an object be shared, or shareable, with other objects, and to what extent may they be peculiar to that object alone?

The first step towards a plausible answer, I suggest, is to note that each individual object will have some properties that are peculiar to it--that set it apart from other objects the same in kind--and that some of these distinguishing properties will be merely contingent ones. Each object will have properties peculiar to it, if only because of the principle that no two objects can, at a time, occupy exactly the same 
place. In addition to spatio-temporal peculiarities, moreover, we commonly find that individual objects-especially the medium-sized objects recognized by common sense--differ qualitatively, if not from all other objects of the same general kind, at least from many. But of the properties that mark off a given individual object from others of its general kind, at least some must be reckoned merely contingent. For regarding them all as necessary threatens to leave no room in the world for properties had just contingently; if there is contingency in the world at all, it is to be found, one would think, in the peculiarities and idiosyncrasies of individual objects. And most philosophers would suppose--contra Spinoza and Leibniz--that the very idea of a property had with necessity requires, for its sense, the contrast of properties had just contingently.

At least some of the properties that distinguish a given object from others similar to it, then, will be properties which the given object merely happens to have. Might others of its distinguishing properties be essential to it? What exactly is the difference between a property by virtue of which a particular object just happens to differ from other similar objects, and a property by which it differs essentially from the others? A large part of the answer, I contend, is that a property by virtue of which an object differs essentially from others is a property with which other properties, that likewise distinguish the given object from those others, reliably cluster together. In other words, a given object differs essentially from certain others only if it differs in a way that matters--in a way that brings other differences in its train.

One argument for this position is pragmatic. The whole point of telling someone that $A$ 's which have $F$ do not just happen to differ from (some or many) other $A$ 's, but differ essentially from those other $A$ 's, is to alert her to the fact that $A$ 's which have $F$ are special in ways beyond just their having $F$--there are inductions which can reliably by run over them, which cannot be run over $A$ 's in general. ${ }^{15}$

A different argument derives from a particular view about the nature of properties and of kinds. According to this view, any genuine property is flanked by its own proper contraries--by properties incompatible with it, which contrast with it to greater and lesser (but commensurable) degrees. ${ }^{16}$ It could not happen, then, that an $A$ having $F$ would also have one of the contraries of $F$. And an $A$ which essentially had $F$--which had $F$ by nature--would be incapable of having any of the contraries; hence any 
$A$ that did have one of the contrary properties would be different in nature from the $A$ 's having $F$. It would belong to a different kind (or sub-kind or variety) of $A$ 's. But then what is it for $A$ 's having one of the contraries-- $G$ or $H$, say--to be different in kind from the $A$ 's having $F$ ? The difference must amount to more than merely not having $F$ itself, and having $G$ instead. That difference would obtain even if the having of $F$ did not amount to an essential difference, a difference in nature, but were merely a matter of having one accidental property rather than a contrary one. That $A$ 's having $G$ or $H$ are different in kind, from $A$ 's having $F$, must mean that they differ in respect of yet other properties, from $A$ 's haying $F$, and do so by nature; kinds are, after all, distinguished only by the properties that characterize them. ${ }^{17}$

The question with which this section began was how closely the essential properties of an individual object can cling to it alone, how widely they must be shared or shareable with other objects. We have discovered no particular limit to how idiosyncratic, how peculiar to it alone, an object's essential properties can be. But we have now found reasons to think that any distinctive or peculiar property essential to an individual object must go together with yet other properties, which likewise distinguish that object from other similar ones.

Can it be essential to any individual object, then, that it be composed of just these (namely, its actual) parts, and no others? Put differently: can it be incompatible with any object's essential nature that it should be composed of parts numerically different from its actual ones, even in the case where the different parts are qualitatively identical with the actual ones? Only if, it would seem, the object's being composed of just these (numerically identified) parts will bring other equally distinctive properties in its train. But that is simply unthinkable. Whatever the properties which an object's composition underlies, and however it underlies them--however the laws of nature work--it is the qualitative character of an object's composition that enables it to underlie the other properties. Qualitatively the same parts, qualitatively the same object. The laws of nature, after all, are indifferent to merely numerical difference: they lay hold of objects by grabbing at the qualities, and on objects (or parts) that are qualitatively just alike, they act in just the same way. Where they determine what will happen to one individual object rather than to others intrinsically just like it, they do so by latching onto extrinsic or relational features of that individual object, in principle repeatable in the case of other individuals. All 
this is in fact beyond controversy; these are platitudes which anchor the very ideas of qualitative sameness, and of laws of nature. (Nor would it matter if the laws of nature could have been different from what in fact they are, a suggestion which--on the interesting reading--I dispute; ${ }^{18}$ so long as there are some laws or other, in a given possible world, the same laws apply to items qualitatively the same as one another.)

This same line of thought shows, it would seem, that no individual material object can necessarily be composed of just this mass of atomless stuff, rather than any other mass qualitatively just alike.

But what of the idea, which a suitably framed example can readily make plausible, that many material objects depend, for their identity over time, on the identity over time of the stuff or the particles that compose them--if not of all the stuff or all the particles, then at least of some? For surely any object must go on being itself, if it is go on being at all. This is true even if an object's numerical identity is no part of its essential nature--even if an "essential nature" is a matter of qualitative features, in principle repeatable in other instances. It is true even if there is, out there in the world, no such property as selfidentity. ${ }^{19}$ For whatever its truth-makers may be, the assertion that a particular object is itself, and is the same object as existed and will exist at all the different phases of its career, must be true of any object. And if its truth, concerning any one material object $T$, consists in the fact that $T$ steadfastly is composed of (all, or at least mainly) just those parts, and no others, however similar--or of just that mass of atomless stuff, and no other, however similar--then the argument of the previous section proves far too much. It will after all be true of $T$ that it necessarily is composed of (all, or at least mainly) just those parts, just that stuff.

Against this objection, my response will be that though the identity over time of many material objects may, depending on the circumstances, require or entail that they are composed continuously of numerically the same parts, it never just consists in that fact. For different circumstances can always be envisioned, in which the identity over time of those same objects permits (or even requires) that they be, 
at different times, composed of numerically different parts. Since those same material objects could exist in those different circumstances, it never is true of them that they necessarily are composed of just those parts, or that stuff.

But let us begin with a suitably framed example. Before me is a large wooden table. I lay my palm on it and ask, "Could this very table have existed here now, if all the wood that composes it had been destroyed by fire ten years ago? Wouldn't there have been a different table here instead--one qualitatively just like the one actually here, just possibly, but still numerically different from this actual one?". And like everyone else, I answer that this table can exist, or have existed, only when and where this wood exists, or existed.

But is this a comment about what the identity over time of this table consists in--or about what it requires, given the way tables are standardly placed in the causal warp and woof of the world? Tables are standardly placed differently in that warp and woof from how living things are. If a chunk of protein is gouged out of my exterior surface--say, by a thorn on a rose bush--processes occurring in my interior will, typically, soon fill in the gouge with new protein, itself obtained (ultimately) from my environment. Familiar facts like this one explain why it has never seemed plausible that the identity over time of a person requires that the particles composing that person be numerically the same across that time. If a table is gouged, in contrast, it typically stays gouged. Tables do not assimilate replacement bits of wood from pencils laid carelessly upon them. So, typically, the only bits of wood present in a table, at a given point in its existence, will be bits that were there from the very start. Typically, no bits will come to compose it, that do not compose it now. Typically, the table has existed, and will exist, only so long as these bits are in it--if not every last one of these bits, then at least most.

But what if this large wooden table, which in fact sits in our graduate seminar room, had instead been put in a different place on our campus, where it received rougher treatment at rowdier hands? This certainly might have happened. This very table might routinely have been gouged and scorched, it might have had graffiti carved into its surface, etc. Might this very table, on such a scenario, have been under the care of an attentive crew of janitors and carpenters? The idea may seem far-fetched, given standard university finances, but it is not rendered impossible by the identity conditions for this table. This very 
table could routinely have had its gouges and graffiti sanded out. It could have happened that, from time to time, the attending carpenters judged it easier to replace a component board than to repair it. The carpenters could have replaced one board or another, without destroying this table. Indeed this very table could have existed now, without containing any of the boards it now contains. They could all have been removed, one by one--and destroyed by fire ten years ago.

Indeed it is even questionable whether a wooden table must depend, for its identity over time, on being wooden--on being composed of some wood or other. Imagine a table, on which the Romans signed some historic treaty with the Jews, being transported, by trireme, across the Dead Sea: a freak storm occurs, the trireme sinks, but the table floats loose unharmed. Eventually it becomes water-logged, sinks to the bottom, and at length the wood composing it turns into "petrified wood". But much later, an undersea expedition is undertaken. The famous table is recovered! --This story is highly fanciful, but it would not seem to be self-contradictory. And note that in this case, the identity over time of the table requires that it no longer be composed of wood at all. The only way this recovered table could be that famous table of ancient lore would be by its having turned into stone; in those salty waters (let us imagine) a wooden table would, after so long a time, have had to turn to stone--any table now composed of wood would be an obvious impostor.

I conclude that the diagnosis I earlier offered is right. The intuition that this table necessarily is composed of this wood responds to, but distorts, the fact that this table is now composed of wood--is now in fact composed of wood, but not necessarily so composed. And why do we have that intuition at all? For much the same reason why it initially seems intuitive that the standard meter bar in Paris necessarily is one meter long. We fix the reference of "this table" by saying that it's the table which now actually is composed of "this wood"; but we do not thereby pick out a necessary property of this table.

But before leaving this section, we must look briefly at an intuition which, for many philosophers, is a close cousin to the one we have so far been discussing. Even if this table might now not have been composed of this very wood--if, indeed, it might now not have been composed of wood at all--is it not still true that this very table would not have existed, had it not at least begun its existence by being made from exactly that wood, from which in fact it was made? If the trees from which its original component 
boards were milled had instead never been felled, could this table have existed? The intuition that the answer to this second question is No--and to the first, Yes--is even stronger than the intuition we have so far discussed. But I maintain that while it too draws its strength from important truths, it too distorts those truths. It is an important truth that an object of an ordinary kind (e.g., an individual table or plank) can have a nature of its own, beyond the properties required for membership in its kind--not just one property beyond those common to the kind, but several, which cluster together for reasons peculiar to its history or its make-up, and do not obtain throughout the kind generally. ${ }^{20}$ Thus this table might have a special rigidity, and a special susceptibility to splitting in just certain ways, that it would not have had, if it had not been made from those individual trees. If so, that would probably be because its component boards would not have had, qualitatively, exactly the grain and the composition they do have, if they had not been milled from just those trees, and indeed milled in just those directions. But even in this case, I maintain, what the nature distinctive of this table (or this plank) consists in are its properties--in principle repeatable--of strength, susceptibility, grain, and composition. Given the way the world works, those properties are likely to have been available from numerically just that source. But its coming from numerically just that source is not an essential property of the table (or the plank). Its coming from numerically just that source is a feature we are right to insist on, in any scenario we will recognize as a possibility for this table (or this plank). But we are right to insist on it just because it is our only ready handle on what may prove, given research, to be properties unique to the table, and which this table has by nature. (Its coming from numerically that source is not, on the view I favor, a property of the table at all, since the would-be "properties" which are incompatible with it--coming from numerically this source, coming from numerically this other source, etc.--do not line up in neatly increasing degrees of contrast, of difference. ${ }^{21}$ ) 
The golden statue of Goliath is now complete, but the labor was arduous. The sculptor thought long about having Goliath's arm point in a different direction, and even about making the statue noticeably smaller. The statue could now have had a different shape and size from what it actually has.

But is there even room in the world for the statue of Goliath? The answer is No, given the ontological assumptions which this paper seeks to defend, if there is, in exactly the place which the putatively real statue occupies, an object which necessarily has, at the present moment, exactly that shape and size.

But can a chunk of gold have exactly that shape essentially--can that shape render it not just contingently different from chunks of gold differently configured, but essentially different? Does having exactly that shape cluster reliably with any other properties, likewise distinctive of that chunk of gold? The answer would seem, in general, to be No. (Exceptions might occur if only a chunk of gold of exactly that shape could float, or be a strong enough arch to support a road; more on this below.)

To the parallel question about size, however, the answer may well be Yes. That a chunk of gold is exactly 8 cubic feet in volume, for example, will go together lawfully with its having a certain distinctive mass, a distinctive capacity for displacing water, even with its exerting a distinctive (although minuscule) gravitational force on other bodies, etc.

But should we take this as showing that chunks of gold of exactly 8 cubic feet in volume have a distinctive essential nature of their own--and that chunks 8.5 cubic feet in volume have their own essential nature, chunks 8.0001 cubic feet in volume theirs, etc.? This would be parallel to saying that Ice, Steam, and Liquid Water constitute distinct natural kinds, each characterized by its own essential nature. Far better, in both cases, to recognize variants or localizations of a single natural kind. ${ }^{22}$ Far more reasonable, that is, to say that there is but a single natural kind, Gold; that gold is a "secondary substance", a stuff, and is by nature such as to occur in variously-sized samples; and that it follows from the unitary essential nature of gold, lawfully and explicably, that each particular size of sample will have such-and-such a mass, such-and-such a displacement, etc.

This sort of position may seem to affirm the reality of brittle objects after all, but in fact it does not do so. A parcel or piece of gold is--to follow the usage of these terms in the philosophical literature, if 
not in common speech--necessarily composed of all and only those individual bits of gold (those atoms or those atomless globs) of which in fact it is composed. This is moreover a priori; it is a priori that a particular parcel of gold (if, indeed, there are parcels of gold) cannot be made smaller or larger. But whether a given sample of gold can be made smaller or larger is an empirical question--likewise, for a sample of any other secondary substance--and the answer generally is Yes. A sample of fissionable uranium (i.e., of U-235) can typically be made larger, but not once it reaches critical mass. A sample of water can typically be made smaller, but not, if current physical theory is correct, smaller than one molecule of $\mathrm{H} 2 \mathrm{O}$. The minimum size for a sample of gold, says current theory, is one atom's worth.

In short, the way one determines what alterations a sample of a secondary substance can and cannot undergo is by doing empirical research on that secondary substance itself. Just discover the ways in which the nature of that secondary substance constrains its occupancy of regions of space, continuously across stretches of time, and you have learned all there is to know about samples of that secondary substance. And this same point suggests the answer to a second worry: even if samples of a given kind of stuff are not themselves brittle objects, do they not still have capacities for lasting (and susceptibilities to destruction) different from those of the familiar objects with which they apparently coincide? The sample of gold found where the statue of Goliath is, for example, will survive even if a vandal melts the statue, and the statue itself will not. ${ }^{23}$ But if all there is to be learned about samples of gold are facts about the stuff's (gold's) capacities for occupying regions of space over time, the answer must be that regarding samples of gold as individuals in their own right is a confusion. There is really just gold, existing at places, for times. That is, the samples lack the individuality which attaches to individual objects of ordinary kinds. An object of an ordinary kind can have, as I remarked above, a nature of its own--a plurality of properties which cluster together for reasons peculiar to its history or its make-up. But not so, for samples of a particular stuff. This would indeed seem the main point of saying (as we do) that gold and water and bronze are stuffs, while there is no one stuff of which dogs (or statues or ships) are all alike composed: the variously (and variably) sized localizations of stuffs show no differences beyond those predicted by their sizes alone. (Or, more exactly, the localizations of any stuff, which are both various and variable as regards both size and shape, show no differences or variations 
beyond those predicted by their sizes and shapes.) In contrast, if there really were such a thing as "dogstuff", ten pounds of it which exactly filled the boundaries of a Yorkshire Terrier would display a very different nature from ten pounds of it excised from a Newfoundland, even if the shapes were perfectly matched.

In sum, the position for which I am arguing denies that there is an object which constitutes the statue of Goliath. There are objects, in the plural, which together constitute Goliath--there are atoms of gold. There is a kind of stuff, gold, such that the statue is composed of it--and so far as this truth goes, gold might have turned out to be a type of atomless gunk. What there is not, is some one something, some individual object, such that it composes the statue.

Before closing, I will briefly contrast the solution offered here, to the problem of coinciding objects, with two others that have recently been proposed. My aim is to show why one might consider the present solution simpler and safer than at least some others.

Michael Burke's solution ${ }^{24}$ maintains that brittle objects do exist in the world, but only where and when they do not also qualify as familiar, mereologically incontinent objects; so coincidence never actually occurs. There are, for example, pieces of copper that are merely pieces of copper, and these cannot come to lose any of the particles of copper they currently contain, nor gain new ones. Indeed Burke is even willing to allow, arguendo, that there is such a thing as the copper composing any given piece--the aggregate of copper atoms, the mass of copper, found exactly where any piece is: like the piece, this object can survive neither diminution nor addition, but unlike the piece can survive dispersal into separate bits. These two objects have the persistence conditions they do in consequence of falling under the sortals "piece of copper" and "aggregate of copper atoms", respectively. ${ }^{25}$ But each of these sortals is "dominated", Burke argues, by the sortal "statue". ${ }^{26}$ That is, when (as one loosely says) the copper or the piece of copper comes, thanks to an artisan, to qualify as "a statue", what really happens is that the former aggregate, and the former piece, get replaced by new ones. And the new ones coincide in 
perfect harmony with the statue: the new aggregate of atoms, and the new piece of copper, last (and can only last) exactly so long as the statue lasts (and can last). If the artisan refashions a copper Goliath so that its arms are more muscular (or less so), that new aggregate and that new piece still exist, addition or diminution notwithstanding. ${ }^{27}$

But Burke's solution would seem vulnerable on two accounts. First, how can it be that some real objects have specific persistence conditions in consequence of satisfying "piece of copper" (or "aggregate of copper"), while other real objects, which satisfy exactly those sortals, have different persistence conditions instead? The switch seems to fight with the very meaning of "in consequence of". Second, does it really make sense to think of a real object's capacities to last through changes, and its vulnerabilities to destruction, as being determined by how language latches on to it? Wouldn't any piece of copper have had the same persistence conditions if lapguages had contained no such sortal as "piece of copper", or even if there had been no languages at all? ${ }^{28}$

Dean Zimmerman offers no finished solution, but advises that the best prospects for saving the reality of familiar objects lie in a "mixed-category" account of how they are constituted by masses. ${ }^{29}$ That is, familiar objects must be regarded as logical constructions out of a world composed fundamentally of brittle objects, or as "disturbances" moving through brittle objects (as a hurricane is a "disturbance" which moves through masses of air). But the "logical construction" account offers little comfort, as Zimmerman recognizes: "if my body is just a function from times to places, then...a function jumping randomly from, say, the metal in the Eiffe $\square$ Tower at one moment to the sugar in my coffee at another is no less 'real', no less a 'persisting thing'". ${ }^{30}$ And the suggestion that my chair, or my boat, is just a "process" or a "disturbance" is no less unsettling: for one thing, I would ask (though Zimmerman would not), how can a disturbance weigh a certain amount? Zimerman's candor makes the very case I would offer for the solution I propose: there are no brittle objects. ${ }^{31}$

$* * * * * * * *$

A Question raised at Bled, June 1997 
Question: Can't we trace the careers of chunks of gold or of clay? Surely, for example, we can meaningfuly ask: did Elder clip a little off Biro's chunk of gold as he carried it to the bank? Or consider (asks Miščević) the massive chunk of stone in Mecca, which Moslems on hegira walk around: if an accident were to befall it, or vandals were to attack it, there would be a question whether the Kaaba stone had been destroyed, or whether it had merely been damaged.

Response: From my point of view, it's always very important to ask: what turns on this question? What does it matter whether this chunk of gold will have continued to exist, under these or those circumstances, or whether it will have been replaced by something else? What properties will this chunk of gold reliably, indeed inevitably, drag with it as it wends its way through time and space?

This is an important question to spotlight because it is easy to give overly hasty answers to it. Here is one way: such-and-such features are the ones I count on to flag or mark out the continued existence of this chunk of gold; therefore such-and-such are properties which this chunk of gold will have, on pain of ceasing to exist at all. -That's a bad inference. [I might flag the continued existence of this man by the feature, being the teacher of Alexander the Great.] Another way: the dictum "this chunk of gold is this chunk of gold" cannot fail to be true, whenever asserted; therefore there's a property, distinctive of just this chunk of gold, which this chunk has necessarily. That's also a bad inference.

The point is that we have a practice, a language game, of saying when a given chunk of stuff has continued to exist, and when it has been replaced by something else. But it's overly hasty to assume that this practice limns reality, or reports a fact-or at least, that it reports exactly that fact it seems to. Where context defines what counts as being the same chunk as containing exactly $70 \%$ or more of the original atoms-where we're really dealing with a type-2 parcel-then the practice does have the function of tracing a fact, where such-and-such atoms are. Where context leaves no particular content to what counts as the same chunk, the situation is different. Here talk of "the same chunk" probably doesn't function to collect history-facts about an individual; it functions to collect quantity-facts about a stuff, gold. Thus one might say, "have we lost some of our gold? Is all the same gold still here? Gold is, after all, expensive!" 
In the case of vandalism on the Kaaba stone, what hangs on the question of that [chunk of] stone's persistence conditions, for the questioners one most readily envisions, is whether walking around whatever remains in that spot (and kissing it, etc.) will be pleasing to Allah. But then, I say, that's really the content of the question. One is asking, "under what circumstances does circling whatever [chunk of] stone remains there please Allah, and under what does it no longer please Allah"? Talk about its still being "the same chunk of stone" does limn a fact (speaking from the standpoint of these questioners), but not the fact it seems to.

\section{Footnotes}

${ }^{1}$ These additional objects divide into parcels and masses, as I point out five sentences farther along, and only in the case of parcels should "cannot be bigger or smaller" be read in the straight spatial sense; in the case of masses, the phrase must be read in a quantitative sense.

${ }^{2}$ With qualifications--stated here at the end of section I--Mark Heller could be said to make such an independent argument, and thereby to be arguing for "additional objects" which are neither quite parcels nor masses, but hunks. See The Ontology of Physical Objects: Four Dimensional Hunks of Matter (Cambridge: Cambridge Univ. Press, 1990), at pp. 53-58.

${ }^{3}$ See, for example, David Wiggins, "On Being in the Same Place at the Same Time," Philosophical Review, (77) 1968, 90-95; or Wiggins, Sameness and Substance (Oxford: Blackwell, 1980), Chapter 1. But the view is very widespread; see footnote 1 in Michael Burke, "Preserving the Principle of One Object to a Place: A Novel Account of the Relations Among Objects, Sorts, Sortals, and Persistence Conditions," Philosophy and Phenomenological Research, 54 (1994), 591-624.

${ }^{4}$ One of the best recent treatments of masses is Dean Zimmerman, "Theories of Masses and Problems of Constitution," Philosophical Review, 104 (1995), 53-110.

${ }^{5}$ Zimmerman, "Theories of Masses," at 67: "every physical object is identical with a mass of some kind--if only a kind for which we do not presently have a name". Each swing in a children's playground, 
for example, is composed of a mass of swing-stuff (68). I think that this abuses our actual common-sense concept of what a stuff is, and that that concept should be protected--it is of some use for science. One criterion for stuffhood we go by, for example, is homogeneity at the level of small parts--a criterion naturally and usefully sharpened, for scientific purposes, as homogeneity on the molecular level. See also the second-to-last paragraph in section $\mathrm{V}$, in the text below.

${ }^{6}$ In addition to the articles by Zimmerman and Burke mentioned so far, see also Burke's "Dion and Theon: an Essentialist Solution to an Ancient Puzzle," Journal of Philosophy, 91 (1994), 129-39. Another important recent paper is Michael C. Rea, "The Problem of Material Constitution," Philosophical Review, 104 (1995), 525-52. Rea is more concerned to taxonomize solutions to the puzzle than to recommend one or another, but he shows far more receptiveness to the ontological assumptions I mention (for a discussion of them, see section I) than would have been typical fifteen years ago, when "sortal dependency" solutions such as Wiggins' dominated the literature.

${ }^{7}$ Even Rea's. To see this, one must dig a bit beneath the text. What Rea says is that denying the existence of aggregates (which, for him, are the paradigm brittle objects) does little to solve "the problem of material constitution" unless one is willing also to deny, across the board, the "Principle of Alternative Compositional Possibilities" (PACP)--the principle that where particles compose an object bearing one modal relation to its constituents, the same particles compose a different object bearing a different modal relation to its constituents $(530, \mathrm{n}$.). What Rea fails to see is that the opponent of brittle objects would love to deny the PACP. For the opponent takes the point of departure, for the PACP, to be familiar objects: he takes the PACP to assert that where particles compose an object (e.g., a ship) which can lose some of its particles, they also compose an object (e.g., an aggregate of wood) which can't. But Rea is so sure there are some brittle objects that he takes them to be the point of departure for the PACP; see 53031 and 550.

${ }^{8}$ But can an individual church go on being a church, if the building with which it originally coincides burns to the ground--if, say, the parish constructs a new building, of different materials, for their worship services? Hume thinks the answer is Yes. To me this seems unintuitive; I would say that 
the parish has built a new church. See Treatise, ed. L. A. Selby-Bigge (Oxford: Oxford Univ. Press, 1888, rpt. 1968), p. 258.

${ }^{9}$ The point is made well by David S. Oderberg, "Coincidence under a Sortal," Philosophical Review, 105 (1996), 145-71.

${ }^{10}$ These are the assumptions most readily contested; there are others. See Burke, "Dion and Theon," 131-34, or Rea, "The Problem," 538-39.

${ }^{11}$ Rea mentions aggregates that are brittle in this diminished sense at 534; Zimmerman considers whether there can be masses capable of losing some components at 78-83.

${ }^{12}$ The claim (at 97) that there can be masses composed of atomless gunk is the most distinctive feature of Zimmerman's theory of masses. For Zimmerman's defense of that claim, see "Could Extended Objects Be Made Out of Simple Parts? An Argument for 'Atomless Gunk'," Philosophy and Phenomenological Research, 56 (1996), 1-29.

${ }^{13}$ Zimmerman, 105-106; cf. 98, 62.

${ }^{14}$ See note 2.

${ }^{15}$ I have offered this argument before: "Laws, Natures, and Contingent Necessities," Philosophy and Phenomenological Research, 54 (1994), at 660-61.

${ }^{16}$ One recent exponent of this view is Ruth Millikan; see Language, Thought, and Other Biological Categories (Cambridge, Mass.: M. I. T. Press, 1984), pp. 268-69 and, more generally, Chapters 16 and 18. I defend the view in various places; for example, "Contrariety and 'Carving Up Reality'," American Philosophical Quarterly, 33 (1996), 277-89, and "Realism and Determinable Properties," Philosophy and Phenomenological Research, 56 (1996), 149-59. But the view goes back to Aristotle, and a major proponent of it is Hegel; for historical references, see footnote 13 of my "An Epistemological Defense of Realism about Necessity," Philosophical Quarterly, 42 (1992), 317-36.

${ }^{17} \mathrm{I}$ have offered this argument before (though in a compressed form)--at 322 of "An Epistemological Defense". Here is an objection to the argument, raised by one referee: the reason for thinking that A's which have $F$ essentially must differ from A's having $G$ or $H$ in more respects than $F$ 
alone is that an essential difference is one which "brings other differences in its train" (as I put it). But then take all the differentiating features of A's having $F$ that are thus "entrained", along with $F$ itself. Together they form a compound property of A's having $F$. Since the compound property is entrained by a feature essential to A's of the special F-bearing kind, it is itself an essential property of those A's. But what further difference (from other A's) does this essential property bring in its train? The only candidates left are accidental differentiae of the special A's, and they obviously won't do. --This interesting objection presupposes that putting two (or more) genuine properties together yields a genuine, if compound, property. I deny this. For my argument, see section I of "Contrariety and 'Carving up Reality"'.

${ }^{18}$ See "Laws, Natures, and Contingent Necessities".

${ }^{19}$ As is argued by Millikan; see Language, Truth,..., p. 197.

${ }^{20} \mathrm{Such}$ a nature consists of properties for which the following sort of inference is non-accidentally reliable (though not infallible): object $O$ has property $F$ at time $t ; \therefore O$ will have $F$ at $t+n$, for any arbitrary $n$. But in general, these properties are not very easily or naturally viewed as essential properties of $O$. The main reason is that the details in $O$ 's history, which explain why the properties in $O$ 's nature cling, clustered, to $O$, sometimes concern events that befall $O$ after $O$ has already existed for a while. But there is no harm in saying that these properties (together) are like an essential nature, which $O$ borrows from the accidents of its fate. That is the strongest sense in which I would claim to have, myself, an individual essence.

${ }^{21}$ See my "Contrariety and 'Carving up Reality'."

${ }^{22}$ For an expanded version of this line of thought, see my "Higher and Lower Essential Natures," American Philosophical Quarterly, 31 (1994), at 258-59.

${ }^{23}$ My thanks to John Troyer for discussion concerning this objection.

${ }^{24}$ "Preserving the Principle of One Object to a Place".

${ }^{25}$ For the phrase "in consequence of", see 600 and 605.

26"Preserving," 605. 
27"Preserving," 618.

${ }^{28}$ For this general pattern of argument, see my "Antirealism and Realist Claims of Invariance," Southern Journal of Philosophy, 29 (1991), 1-19. "But what about statues and chairs," the reader might ask; "aren't their persistence conditions determined by what we say, rather than by nature?". No, I have argued; even their persistence conditions are determined by nature--though the contrast with "what we say" is half-spurious. See "A Different Kind of Natural Kind," Australasian Journal of Philosophy, 73 (1995), 516-31, and "Realism, Naturalism, and Culturally Generated Kinds," Philosophical Quarterly, 39 (1989), 425-44.

29"A Theory of Masses"; see, for example, last paragraph.

30"A Theory," 92.

${ }^{31}$ Heartfelt thanks to John Troyer for discussion of earlier versions. Thanks also to Don Baxter for help with Hume, and to anonymous referees for instructive and challenging objections. 